\title{
Disseminated Cooccidiomycosis in Dogs in Cauvery Delta Region of Tamilnadu: A Zoonotic Concern
}

\author{
B. Puvarajan*, T. Lurthu Reetha, B.S.M. Ronald, R. Manickam and P. Ponnusamy \\ Department of Veterinary Microbiology, Veterinary College and Research Institute, \\ Orathanadu 614625, Tamilnadu, India \\ *Corresponding author
}

\section{A B S T R A C T}

\section{Keywords}

Coccidiodomycosis-Dog-

Dysjunctors-

Disseminated form

Article Info

Accepted:

04 July 2018

Available Online:

10 August 2018
Coccidioidomycosis a zoonotic fungal infection caused by the dimorphic fungus Coccidioides immitis acquiring from environment through the risk of exposure to infectious arthrospores with subclinical or clinical which is affecting the dogs reared in house with less exposure to sun. The present report describes the disseminated form of coccidiomycosis in Labrador dogs which affected the cutaneous, osseous, cardiac, ocular, nervous system, or other organ with variable clinical symptoms and so far not recorded in this Cauvery Delta region of Tamilnadu. The diagnosis was established by fungal culture and identification by microscopy and clinical assessment. The microscopic demonstration of dysjunctors of arthrospores arrangement and the fungal isolation along with histopathological examination proved to be a useful tool in presumptive diagnosis of Coccidiomycosis in Labrador Dogs.

\section{Introduction}

Coccidiomycosis in dogs primarily a respiratory fungal infection caused by C.immitis and systemic dissemination lead to malignancy in dogs being chronic in nature. Moreover Coccidiomycosis is highly relevant to public health and confines the fungus to limted zones of high endemicity. Coccidioidomycosis should be considered in any dog or cat that has been potentially exposed during the previous 3 years along with chronic illness, respiratory signs, lameness, lymphadenopathy, non-healing cutaneous lesions, or neurological, ocular, or cardiac abnormalities. The Coccidioides genus is considered dimorphic. Dimorphism is characterized by production of filamentous (mycelial) forms by certain fungi during their saprophytic phase in the environment or when incubated at lower temperatures on media. Serological titers support the diagnosis, but definitive diagnosis relies on identification of Coccidioides in cytological or tissue samples. Infections caused by Coccidioides may be subclinical or result in severe illness and death. Dissemination to extrapulmonary organs is a potential sequela in some animals. This is a report experienced in our region as disseminated form of Coccidiodes infection in Labrador dogs. In this report, we analysed the dermatitis cases susceptive of chronic alopecia for a period of three months in Labrador dogs residing in kennels and brought to the camps 
conducted for animal owners in this Cauvery Delta region. This research paper reports an presumptive diagnosis of Coccidiodes in Labrador dogs based on colonial morphology, staining characters and clinical conditions with evidence of histopathology from the skin tissues for confirmation.

\section{Materials and Methods}

Twenty Labrador dogs in kennels in this region were reported of severe alopecia (Fig 3) and a mass on the thoracic region (right side) within a minor swelling of the surrounding soft tissue. Disease investigation was conducted and skin scrapings were collected from the right abdominal region, behind the knees and dorsal portion of the shoulder and treated with 10\% Potassium hydroxide for tissue clarification. The scrapings were simultaneously spread over the Sabarouds dextrose agar and incubated for 24 -72 hours and the colonial morphology was observed. (Akram and Koirala, 2017; Sutton, 2007). Tissue biopsy was done and a portion was processed for histopathological examination. For presumptive diagnosis, two small $(0.3-0.5 \mathrm{~cm})$ tissues were taken from affected areas, fixed in $10 \%$ buffered formalin and submitted to histopathological examination. (Romero et al., 2016)

\section{Results and Discussion}

Among 20 dogs examined, thirteen numbers were confirmed of coccidiomycosis by the clinical and laboratory findings such as colonial morphology and histopathological examination.

Microscopic examination revealed that the organism Coccidioides immitis characterized by septate hyphae and thick-walled arthroconidia ( 2 by $4 \mathrm{~m}$ ) that are formed along the length of the hyphae (enteroarthric development) with empty, thin-walled, brittle disjunctors of arthroconidia along the hyphae.
(Fig 1 and 2). These arthroconidia can be easily released into the air by soil disruption and when inhaled into lungs or on occasions get into percutaneous implantation into tissue. Arthroconidia, the infectious particles of Coccidiosis species are deposited in the lung when inhaled. Arthroconidia transform to spherules in the lung and tissues. Spherules are filled with endospores ( 2 micrometers to 5 micrometers).

This spherule can burst in tissues releasing endospores, which can magnify the infection. On histopathological examination, the presence of oval spherules, which enlarge and undergo endosporulation are noticed. They are $10-40 \mu \mathrm{m}$ diameter with thick retractile walls containing small bodies called endospores. The evidence of these spores indicates the local granulomas as per the findings of Tortorano et al., 2012. Moreover each arthroconidium transforms into a new multinucleated, spherical structure called the spherule.

This structure increases in size and forms a thick outer wall. As it grows, the spherule begins to divide internally by invagination and formation of cleavage furrows, culminating in the production of numerous uninucleated endospores. Spherules vary from 60 to over $100 \mathrm{~m}$ in diameter, while endospores remain 2 to $5 \mathrm{~m}$ in size. Mature spherules may contain 800 to 1,000 endospores, which are released into tissue upon the spherule's rupture. (Malo, 2014).

These findings are consistent with a diagnosis of disseminated coccidioidomycosis with cutaneous, vertebral, and pulmonary involvement (Sinke and Sjollema, 1994; Guarner and Brandt, 2011; Laborin et al., 2012; Raghu and Reagh, 2018.) Diagnosis of coccidioidomycosis in dogs can be challenging because the symptoms are not specific for this diseases. 
Fig.1 and 2 Showing disjunctors of arthroconidia along the hyphae under oil immersion optical Microscope, Nikon, Japan
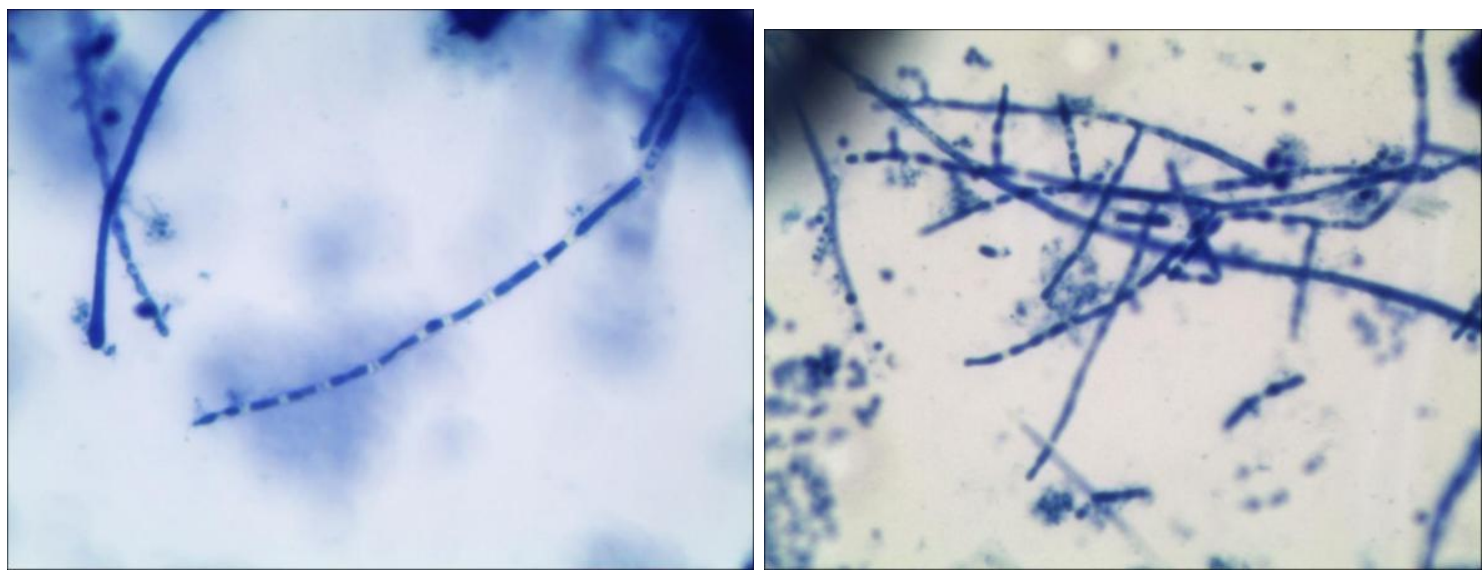

Fig.3 Clinical picture of severe alopecia in Labrador dog suspected for coccidiodomycosis

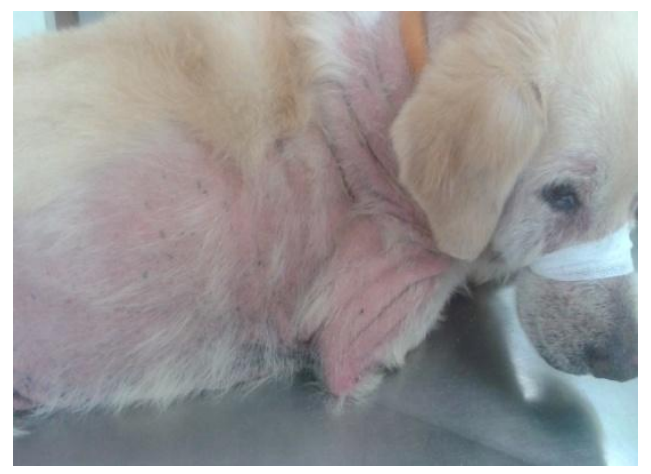

In humans, Coccidioides can remain dormant for several years and can become an active infection as the patient ages or becomes immunocompromised (Brown, 2013; Hector, 2011).

This case report further highlights the importance of a detailed travel history beyond the past four years and consideration of infectious diseases that are non-endemic to the present residence.

The report of Coccidiomycosis in this Cauvery delta region suspects that purchase of exotic breeds along with increased mobility of owners from neighbouring foreign countries may also be one of the reasons for occurrence of Coccidiomycosis.

\section{Acknowledgement}

The help and cooperation rendered by the Veterinary Assistant Surgeons, The Joint Director, Animal Husbandry, Thanjavur District and the line departments in Cauvery Delta region for collection of samples in this study is highly appreciated and acknowledged.

\section{References}

Akram, S.M and Koirala. J. (2017). Coccidioidomycosis. Stat Pearls Book shelf. NCBI Resources.

Guarner J and Brandt, M.E. (2011). Histopathological diagnosis of fungal infections in the $21^{\text {st }}$ century. 
Clin.Microbial.Rev.24() 2):247-280.doi 10.1128/CMR.00053-10.

Hector, RF., Rutherford, G.W., Tsang, CA., Erhart, LM Mc cotter O and Anderson, S.M. 2011. The public health impact of coccidioodomycosis in Arizona and California. Int.J.Env.Res.Pub Health 8(4): 1150-73.

Laborin, L.R, A; Cantar Sramm, J.M; Adame, CR. Coccidiodomycosis: an update Curr. FungalInfect Rep. doi;10.1007/ s12281-12-0084-z.

Malo, J. Monjagatta, L.C., Thompson, R., Hage, C.A., Knox, KS. 2014. Update on the diagnosis of pulmonary coccidiodismycosis. Ann Am Thorac Soc. 11(2): 243-53. doi:10.1513/Annals ATS. 201308-286FR.

Quinn, P.J., Markey, B.K Leonard, F.C., Fitzpatrick, and Fanning, S.E.S., (2015). Concise review of Veterinary Microbiology. Wiley Blackwell $2^{\text {nd }}$ Edn. USA

Raghu, C and Reagh, C. (2018). Novel Treatment of Disseminated Coccidioidomycosis in a Dog with Voriconazole. Case Reports in Veterinary Medicine. Article ID 1785748, 6 pages https://doi.org/ 10.1155/2018/1785748

Romero, R.R, Perez, R.R., Arias, J.L., Quintana, J.L., and Mayagoitia, A.L. (2016). Coccidioidomycosis in Biopsies with Presumptive Diagnosis of Malignancy in Dogs: Report of Three Cases and Comparative Discussion of Published Reports. Mycopathologia 181:151-57.

Saubolle, M. A. (2000). Mycology and the clinical laboratory in the diagnosis of respiratory mycoses, p. 1-16. In G. A. Sarosi and S. F. Davies (ed.), Fungal diseases of the lung. Lippincott Williams \& Wilkins, Philadelphia, PA.

Saubolle, M.A., Mc Keller, P.P and Sussland, D. (2007). Epidemiologic, Clinical, and Diagnostic Aspects of Coccidioidomycosis. j. OF Clinical Microbiology, 45(1),26-30.

Sinke, J.D and Sjollema, B.E. 1994. Coccidioidomycosis in a dog. The veterinary quarterly $16(1)$ : $64 \mathrm{~S}$.

Sutto, DA. 2007. Diagnosis of coccidiomycosis by culture: safety considerations, traditional methods and susceptibility testing. Ann. NY. Acad. Sci. 1111: 315-25.

The Centre for Food security and Public Health. 2010. Coccidiomycosis, IOWA State University. pp. 1-9.

Tortorano AM, Carminati G, Tosoni A (2012). Primary cutaneous Coccidioidomycosis in an Italian nun working in South America and review of published literature. Mycopathologia 2015; 180: 229-235.

\section{How to cite this article:}

Puvarajan, B., T. Lurthu Reetha, B.S.M. Ronald, R. Manickam and Ponnusamy, P. 2018. Disseminated Cooccidiomycosis in Dogs in Cauvery Delta Region of Tamilnadu: A Zoonotic Concern. Int.J.Curr.Microbiol.App.Sci. 7(08): 61-64. doi: https://doi.org/10.20546/ijcmas.2018.708.007 